\title{
Association of Helicobacter pylori with HLA-DR antigen expression in gastritis
}

\author{
A Wee, M Teh, J Y Kang
}

\begin{abstract}
Aims: To assess the association between Helicobacter pylori-associated gastritis and HLA-DR antigen (class II antigen) expression.

Methods: Fifty endoscopic gastric biopsy specimens were studied for the presence of $H$ pylori, degree and type of inflammation, and for HLA-DR antigen expression in the epithelium. The cases were chosen to represent different categories: inflamed gastric mucosa with $(n=13)$ and without $(n=20) H$ pylori, and non-inflamed mucosa $(n=17)$.
\end{abstract}

Results: The antigen was aberrantly expressed in the antral mucosal epithelium in 11 of 12 cases $(92 \%)$ with acuteon-chronic gastritis when $\boldsymbol{H}$ pylori was also present. It was present in the antrum in only seven of $18 \mathrm{H}$ pylori negative cases (39\%) with acute-on-chronic/chronic gastritis. One of three cases of acute gastritis and three of seven cases of chronic gastric erosions (non-inflamed category) showed positive staining. Generally, there was more staining in the antral than body mucosa and in the surface/foveolar epithelium than in the glands. No aberrant HLA-DR antigen expression was found in the 10 cases of normal gastric mucosa examined.

Conclusions: These findings suggest that $H$ pylori may have a role in the induction of class II HLA antigen expression in chronic gastritis and lend support to the view that these organisms may be responsible for part of the inflammatory response.

Class II HLA antigens are the products of the HLA-DR, DQ, and DP genes, and are located in the HLA-D region. Unlike class I HLA antigens, they have a more restricted distribution and are known to be strongly present in cells associated with the human immune response-monocytes/macrophages, dendritic antigen-presenting cells such as Langerhans' cells, B lymphocytes and activated T lymphocytes. ${ }^{1}$ They have also been shown to be present in other tissues, both normal and pathological. ${ }^{12}$ While class II HLA antigens are absent in the epithelial cells of normal gastric mucosa, they are present in the inflamed mucosa of chronic gastritis. ${ }^{34}$ Previous studies have also shown a direct link between epithelial HLA class II antigen expression and the intraepithelial, as well as the lamina propria, density of T lymphocytes. ${ }^{5}$ This suggests a causal role for the $T$ cells, probably via a lymphokine such as gamma interferon, because this substance has the ability to induce the transcription of HLA class II antigens. ${ }^{16}$

Numerous studies have also attested to the very strong link between colonisation of the gastric mucosa by Helicobacter pylori and gastritis; particularly so when the gastritis is "active". The prevalence of $H$ pylori ranges from $70 \%$ to $90 \%$ in active chronic gastritis but falls to as low as $6 \%$ in inactive cases..$^{7-9}$ The accumulated evidence to date suggests that these organisms may have an aetiological role in the pathogenesis of chronic gastritis. ${ }^{10}$ The presence of $H$ pylor $i$ in the gastric mucosa could therefore give rise to a primary immune reaction $^{11}$ with $\mathrm{T}$ cell activation and subsequent induction of HLA class II antigens in the affected gastric epithelium. This study attempts to see if a link exists between the presence of $H$ pylor $i$ in the gastric mucosa and HLA-DR antigen in the affected epithelium.

\section{Methods}

Altogether, 50 endoscopic gastric biopsy specimens were selected from department files from January 1984 to March 1991. They were taken from patients who had undergone gastroduodenoscopy for gastrointestinal symptoms. Informed consent had been obtained. Patients with gastric carcinoma were excluded. All of the biopsy specimens included at least one piece of antral as well as one piece of body mucosa. When focal abnormalities such as inflammatory changes or erosions were present, the biopsy specimen was taken from the abnormal area. Otherwise the specimens were taken from the lesser curve mid-antrum and greater curve mid-body. These cases were chosen to represent different categories: inflamed gastric mucosa with and without $H$ pylori, and non-inflamed mucosa. The specimens were fixed in $10 \%$ buffered formalin. Paraffin wax embedded sections were cut at $4 \mu \mathrm{m}$ and stained with haematoxylin and eosin and by periodic acid-Schiff.

\section{HISTOLOGICAL ASSESSMENT}

Histological gastritis was defined by a modification of the system used by McNulty et $a l^{12}$ which has been described in detail previously. ${ }^{13}$ In brief, mononuclear and polymorphonuclear cellular infiltration were each graded from 0 to 4 . If the acute inflammatory score was 1 or more, or the chronic 
inflammatory score were 3 or more, gastritis was said to be present. Gastritis was said to be acute if the polymorphonuclear cellular score was 1 or more with a mononuclear cellular score of under 3. Chronic gastritis was diagnosed if the mononuclear cellular infiltrate was 3 or more while the acute inflammatory score was 0 . Acute-on-chronic inflammation was diagnosed when the acute and chronic inflammatory scores were greater than 0 and 2, respectively. The occurrence of glandular atrophy and intestinal metaplasia were recorded separately.

Non-inflamed mucosa was further subdivided into normal gastric mucosa and chronic gastric erosions. Chronic gastric erosions were recognised by the presence of papillary surface and increased capillary vascularisation in the superficial lamina propria in a setting of minimal inflammatory cellular infiltrate. The presence or absence of $H$ pylori was assessed using the haematoxylin and eosin stain as we have found that this is as effective as the Giemsa method. ${ }^{813} \mathrm{~A}$ blind review by the same pathologist (AW) of 24 consecutive antral biopsy specimens stained with haematoxylin and eosin and read on two separate occasions showed agreement in all cases. Another blind comparison of serial sections of 126 consecutive antral biopsy specimens stained with haematoxylin and eosin and with Giemsa showed agreement in $123(98 \%)$. Although bacteriological culture was not routinely used in this study, we had previously found a good correlation between histological and bacteriological identification of H pylori. ${ }^{14}$

\section{IMMUNOPEROXIDASE STAINING FOR HLA-DR ANTIGEN}

Sections $4 \mu \mathrm{m}$ thick were subsequently cut and stained for the presence of HLA-DR antigens using the streptavidin-biotin method with a commercially available mouse monoclonal antibody (Dako-HLA-DR/Alpha) at a concentration of 1 in 50. The staining patterns of the gastric surface/foveolar epithelium and glandular epithelium were evaluated separately for the extent of staining using a three-point system. This was based on the percentages of epithelial cells staining positively in their respective locations: 0 (no staining), $1+$ (less than $10 \%), 2+(10-50 \%)$ and $3+(>50 \%)$. The positive staining of the histiocytes/lym- phocytes in the lamina propria provided the necessary positive control while the biopsy specimens from the normal gastric mucosa acted as negative controls.

Data were analysed by Fisher's exact test and the two-sided probability value obtained. Probability values of $<0.05$ were regarded as significant.

\section{Results}

Of the 50 gastric biopsy specimens examined, gastritis was diagnosed in the antrum or body mucosa, or both, of 33 patients (table 1). Twenty four of them had acute-on-chronic gastritis; six showed only chronic gastritis; and three only acute inflammation. The remaining 17 cases consisted of either normal gastric mucosa (10), or chronic gastric erosions (7) with no significant inflammatory component. $H$ pylori was identified in 13 specimens- 12 showing acute-on-chronic gastritis and one acute gastritis. No organisms were identified in the non-inflamed category.

HLA-DR antigen staining, when present, was cytoplasmic with a membranous component of variable intensity. Generally, it tended to be more positive in the antrum than in the body and was more often expressed in the surface/ foveolar than in the glandular epithelium (table 2).

\section{INFLAMED GASTRIC MUCOSA}

Acute-on-chronic gastritis with $H$ pylori

There was unequivocal HLA-DR staining in the antrum in 11 out of 12 cases (92\%) with $H$ pylori (table 2) (Figure). Staining tended to be extensive for this category with most showing either $2+$ or $3+$ staining in the antral surface/ foveolar epithelium. Overall, there was less staining in the body mucosa, with only eight cases $(67 \%)$ showing unequivocal positivity in the surface/foveolar epithelium; half showed $1+$ staining. For both the antral and body types of mucosa, HLA-DR antigen was more likely to be expressed in the surface/foveolar epithelium rather than in the glandular epithelium.

Acute-on-chronic and chronic gastritis without $H$ pylori

There were 18 cases in this category. The degree of chronic inflammation was compar-

Table 1 Helicobacter pylori and type of gastric mucosa

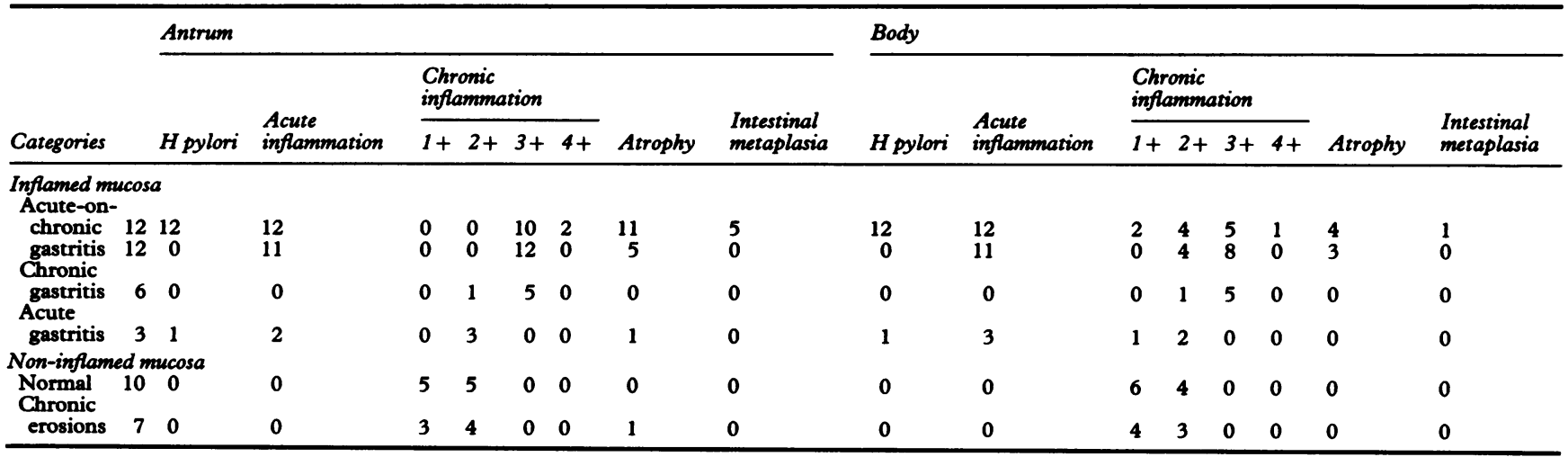




\begin{tabular}{|c|c|c|c|c|c|c|c|c|c|c|c|c|c|c|c|c|c|}
\hline \multirow[b]{3}{*}{ Categories } & & \multicolumn{8}{|c|}{ Antrum } & \multicolumn{8}{|c|}{ Body } \\
\hline & & \multicolumn{4}{|c|}{$\begin{array}{l}\text { Surface/foveolar } \\
\text { epithelium }\end{array}$} & \multicolumn{4}{|c|}{$\begin{array}{l}\text { Glandular } \\
\text { epithelium }\end{array}$} & \multicolumn{4}{|c|}{$\begin{array}{l}\text { Surface/foveolar } \\
\text { epithelium }\end{array}$} & \multicolumn{4}{|c|}{$\begin{array}{l}\text { Glandular } \\
\text { epithelium }\end{array}$} \\
\hline & & 0 & $1+$ & $2+$ & $3+$ & 0 & $1+$ & $2+$ & $3+$ & 0 & $1+$ & $2+$ & $3+$ & 0 & $1+$ & $2+$ & $3+$ \\
\hline \multicolumn{18}{|l|}{ Inflamed mucosa } \\
\hline $\begin{array}{l}\text { Acute-on-chronic gastritis } \\
\text { Chronic gastritis } \\
\text { Acute gastritis }\end{array}$ & $\begin{array}{l}12 \text { ( } H \text { pylori positive) } \\
12 \text { ( } H \text { pylori negative) } \\
6 \\
3^{\star}\end{array}$ & $\begin{array}{l}1 \\
7 \\
4 \\
2\end{array}$ & $\begin{array}{l}2 \\
2 \\
2 \\
0\end{array}$ & $\begin{array}{l}\mathbf{5} \\
\mathbf{3} \\
\mathbf{0} \\
\mathbf{0}\end{array}$ & $\begin{array}{l}4 \\
0 \\
0 \\
1\end{array}$ & $\begin{array}{l}8 \\
9 \\
5 \\
2\end{array}$ & $\begin{array}{l}1 \\
1 \\
0 \\
1\end{array}$ & $\begin{array}{l}1 \\
0 \\
1 \\
0\end{array}$ & $\begin{array}{l}2 \\
2 \\
0 \\
0\end{array}$ & $\begin{array}{l}4 \\
8 \\
6 \\
2\end{array}$ & $\begin{array}{l}4 \\
4 \\
0 \\
1\end{array}$ & $\begin{array}{l}2 \\
0 \\
0 \\
0\end{array}$ & $\begin{array}{l}2 \\
0 \\
0 \\
0\end{array}$ & $\begin{array}{l}9 \\
9 \\
6 \\
1\end{array}$ & $\begin{array}{l}3 \\
2 \\
0 \\
2\end{array}$ & $\begin{array}{l}0 \\
1 \\
0 \\
0\end{array}$ & $\begin{array}{l}0 \\
0 \\
0 \\
0\end{array}$ \\
\hline $\begin{array}{l}\text { Non-inflamed mucosa } \\
\text { Normal } \\
\text { Chronic erosions }\end{array}$ & $\begin{array}{r}10 \\
7\end{array}$ & $\begin{array}{r}10 \\
4\end{array}$ & $\begin{array}{l}0 \\
1\end{array}$ & $\begin{array}{l}0 \\
1\end{array}$ & $\begin{array}{l}0 \\
1\end{array}$ & $\begin{array}{r}10 \\
5\end{array}$ & $\begin{array}{l}0 \\
0\end{array}$ & $\begin{array}{l}0 \\
1\end{array}$ & $\begin{array}{l}0 \\
1\end{array}$ & $\begin{array}{r}10 \\
7\end{array}$ & $\begin{array}{l}\mathbf{0} \\
\mathbf{0}\end{array}$ & $\begin{array}{l}0 \\
0\end{array}$ & $\begin{array}{l}0 \\
0\end{array}$ & $\begin{array}{r}10 \\
7\end{array}$ & $\begin{array}{l}0 \\
0\end{array}$ & $\begin{array}{l}0 \\
0\end{array}$ & $\begin{array}{l}0 \\
0\end{array}$ \\
\hline
\end{tabular}

*One case showed $H$ pylori and HLA-DR antigen staining of the epithelium in both sites.

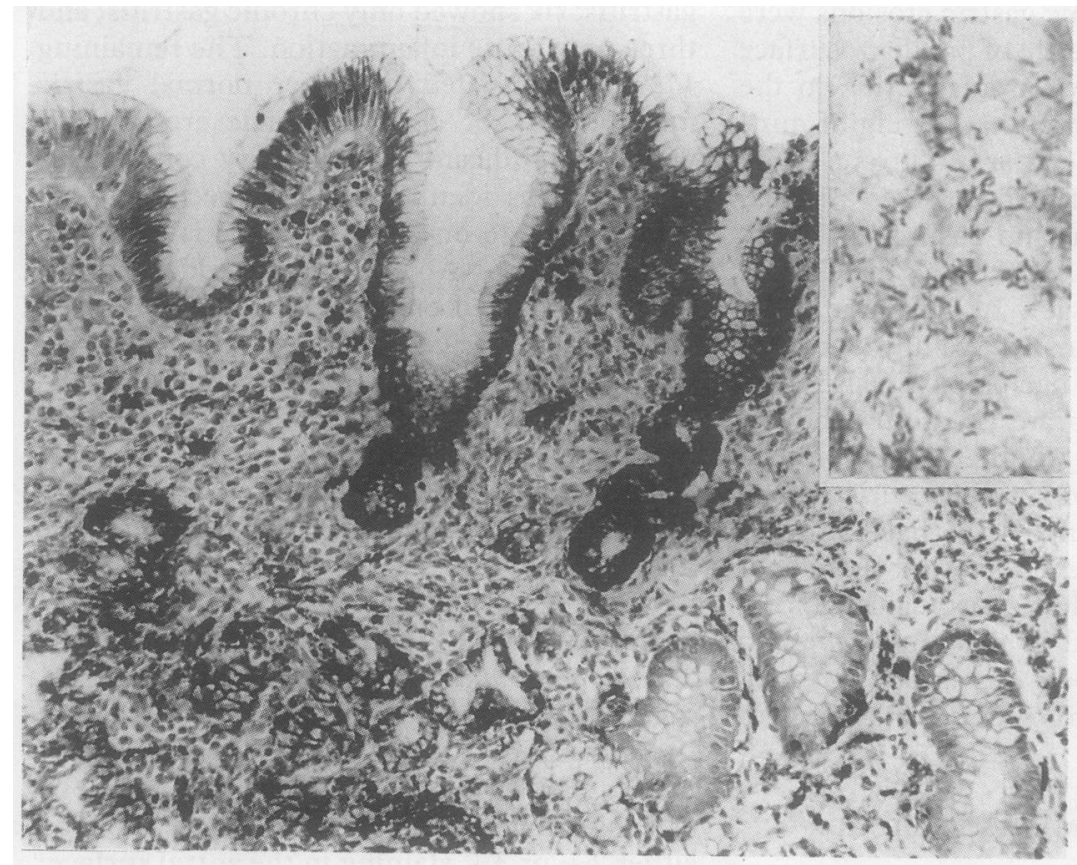

Immunoperoxidase staining of $H L A-D R$-reactive cells in the antral mucosa of a patient with $H$ pylori-associated acute-on-chronic gastritis. Note intense staining of the epithelial cells in the surface/foveolar epithelium on the right and glandular epithelium on the left. Inset: $H$ pylori colonisation of the gastric mucous layer (haematoxylin and eosin). extensive for this category: no case showed $3+$ staining in either the antrum or body. Again, the staining tended to be localised mainly to the surface/foveolar epithelium of the antrum.

\section{Acute gastritis}

One of the three cases expressed HLA-DR antigen in the surface/foveolar and glandular epithelium in both the antrum and body mucosa. This case was positive for $H$ pylori. The other two cases were negative for $H$ pylori; one of them showed only $1+$ antigen staining and this was restricted to the glands in the body region (table 2).

\section{NON-INFLAMED GASTRIC MUCOSA}

Normal gastric mucosa

The 10 cases studied were negative for HLADR antigen (table 2).

\section{Chronic gastric erosions}

Of the seven cases, only three (43\%) expressed HLA-DR antigen in the antrum (table 2). There was no significant inflammation in these cases (table 1).

\section{Discussion}

The aberrant expression of HLA class II antigens in chronic gastritis has been documented. ${ }^{34}$ Using a monoclonal antibody that is reactive to paraffin wax blocked tissue, we have similarly found abnormal expression of HLADR antigen in inflamed gastric mucosa. Of interest is the fact that there seems to be a discrepancy in the HLA-DR antigen expression between equally chronically inflamed gastric mucosa with and without $H$ pylori. This would strongly suggest that $H$ pylori may have an aetiological role in the induction of class II HLA antigens in gastric epithelial cells. The presence of foreign bacterial antigens could possibly initiate a local immune reaction ${ }^{11}$ leading to the activation of immune cells like $\mathrm{T}$

Table 3 Comparison of HLA-DR antigen expression in acute-on-chronic and chronic gastritis with and without $H$ pylori

\begin{tabular}{|c|c|c|c|c|c|c|c|c|c|c|c|c|c|c|c|c|c|}
\hline \multirow[b]{3}{*}{ H pylori } & & \multicolumn{8}{|c|}{ Antrum } & \multicolumn{8}{|c|}{ Body } \\
\hline & & \multicolumn{4}{|c|}{$\begin{array}{l}\text { Surface/foveolar } \\
\text { epithelium }\end{array}$} & \multicolumn{4}{|c|}{$\begin{array}{l}\text { Glandular } \\
\text { epithelium }\end{array}$} & \multicolumn{4}{|c|}{$\begin{array}{l}\text { Surface|foveolar } \\
\text { epithelium }\end{array}$} & \multicolumn{4}{|c|}{$\begin{array}{l}\text { Glandular } \\
\text { epithelium }\end{array}$} \\
\hline & & 0 & $1+$ & $2+$ & $3+$ & 0 & $1+$ & $2+$ & $3+$ & 0 & $1+$ & $2+$ & $3+$ & 0 & $1+$ & $2+$ & $3+$ \\
\hline $\begin{array}{l}\text { Present } \\
\text { Absent }\end{array}$ & $\begin{array}{l}12 \\
18\end{array}$ & $\begin{array}{r}1 \\
11\end{array}$ & $\begin{array}{l}2 \\
4\end{array}$ & $\begin{array}{l}\mathbf{5} \\
\mathbf{3}\end{array}$ & $\begin{array}{l}4 \\
0\end{array}$ & $\begin{array}{r}8 \\
14\end{array}$ & $\begin{array}{l}1 \\
1\end{array}$ & $\begin{array}{l}1 \\
1\end{array}$ & $\begin{array}{l}2 \\
2\end{array}$ & $\begin{array}{r}4 \\
14\end{array}$ & $\begin{array}{l}4 \\
4\end{array}$ & $\begin{array}{l}2 \\
0\end{array}$ & $\begin{array}{l}2 \\
0\end{array}$ & $\begin{array}{r}9 \\
15\end{array}$ & $\begin{array}{l}3 \\
2\end{array}$ & $\begin{array}{l}0 \\
1\end{array}$ & $\begin{array}{l}\mathbf{0} \\
\mathbf{0}\end{array}$ \\
\hline
\end{tabular}


lymphocytes, with subsequent release of gamma interferon and/or other lymphokines/ cytokines which are capable of inducing class II HLA antigen expression. In this respect it is interesting to note that previous work had shown a direct correlation between the degree of HLA-DR activation and the number of activated $\mathrm{T}$ lymphocytes present. ${ }^{5}$

It is already known that the more active the gastritis in terms of the intensity of the polymorphonuclear cellular infiltrate, the more likely it is that $H$ pylori will be found. Polymorphonuclear neutrophils probably did not have a significant role in HLA-DR induction, however, as the main lymphokine/cytokine purported to be responsible for the induction of class II HLA antigens in vivo is gamma interferon. HLA-DR expression in chronic gastritis also remained low when $H$ pylori was not present, even for those cases where there was concomitant acute inflammation (table 3 ). The overall degree of acute inflammation, however, as determined by the acute inflammatory score, was less than that for the cases of gastritis in which $H$ pylori was present. It is also relevant that of the three cases showing acute inflammation alone, the only case that had extensive HLA-DR expression also contained $H$ pylori. The acute inflammatory score was also very high for this particular case.

As expected, normal gastric mucosa did not show any HLA-DR expression. Three of the seven cases of chronic gastric erosions included under the non-inflamed category, however, showed aberrant HLA-DR expression. The staining was identified in the antrum and graded as $1+, 2+$, and $3+$, respectively. A possible explanation is that this could have been due to a prevous inflammatory episode which had subsequently become quiescent. The aberrant antigen, once induced, however, may remain within the epithelial cells for some time.

Thus it would seem from our studies that chronic gastritis is associated with aberrant HLA-DR expression. In some cases the inflammation has since subsided. A strong correlation was found between the presence of HLA-DR antigen expression and $H$ pylori, providing further evidence that these organisms may have a primary role in its induction by evoking a host immune response.

We thank Mr C K Ow for technical work, MR T C Tan for photography, and Mrs A T Mok for typing the manuscript.

1 Bodmer WF. The HLA system: structure and function. $J$ Clin Pathol 1987;40:948-58.

2 Klareskog L, Forsum U. Tissue distribution of class II transplantation antigens: presence on normal cells. In Solheim BG, Moller E, Ferrone S, eds. HLA class II antigens. A comprehensive review of structure and function. Berlin: Springer-Verlag, 1986:339-55.

3 Engstrand L, Scheynius A, Pahlson C, Grimelius L, Schwan A, Gustavsson S. Association of Campylobacter pylori with induced expression of class II transplantation antigens on gastric epithelial cells. Infect Immun 1989; 57:827-32.

4 Spencer J, Finn T, Isaacson PG. Expression of HLA-DR antigens on epithelium associated with lymphoid tissue in the human gastrointestinal tract. Gut 1986;27:153-7.

5 Valnes K, Huitfeldt HS, Brandtzaeg P. Relation between T cell number and epithelial HLA class II expression quantified by image analysis in normal and inflamed human gastric mucosa. Gut 1990;31:647-52.

6 Collins T, Pober JS, Strominger JL. Physiologic regulation of class II major histocompatibility complex gene expression. In: Solheim BG, Moller E, Ferrone S, eds. HLA class II antigens. A comprehensive review of structure and function. Heidelberg: Springer-Verlag, 1986:14-31.

7 Rawles JW, Paull G, Yardley JH, et al. Gastric campylobacter-like organisms in a US hospital population. Gastroenterology 1986;91:1599A.

8 Kang JY, Wee A, Math MV, et al. Helicobacter pylori and gastritis in patients with peptic ulcer and non-ulcer dyspepsia: ethnic differences in Singapore. Gut 1990; 31:850-3.

9 Goodwin CS, Armstrong JA, Marshall BJ. Campylobacter pyloridis, gastritis and peptic ulceration. J Clin Pathol 1986;39:353-65.

10 McKinlay AW, Upadhyay R, Gemmell CG, Russell RI Helicobacter pylori: bridging the credibility gap. Gut 1990;31:940-5.

11 Wyatt JI, Rathbone BJ, Heatley RV. Local immune response to gastric Campylobacter in non-ulcer dyspepsia. $J$ ponse to gastric Campylobact

12 McNulty CAM, Gearty JC, Crump B, et al. Campylobacter pyloridis and associated gastritis: investigator blind, placebo controlled trial of bismuth salicylate and erythromycin ethylsuccinate. $B r M e d J$ 1986;293:645-9.

13 Wee A, Kang JY, Ho MS, Choong HL, Wu AYT, Sutherland IH. Gastroduodenal mucosa in uraemia: endoscopic and histological correlation and prevalence of helicobacter-like organisms. Gut 1990;10:1093-6.

14 Yap I, Kung JSL, Wee A, et al. Comparison of culture and histology for the identification of Helicobacter pylori in endoscopic biopsies. Ann Acad Med Sing 1990;19:354-6. 